\title{
Justiça Restaurativa e Prisões: sobre uma política pública de prevenção e de enfrentamento da violência institucional
}

\author{
Justicia Restaurativa y Prisiones: una política pública de prevención y de \\ lucha contra la violencia institucional \\ Restorative Justice and Prisons: a public policy to prevent and combat the \\ institutional violence
}

\section{Aline Santestevan Oliveira Iribarrem ${ }^{1}$}

\begin{abstract}
Resumo
Este trabalho foi desenvolvido a partir de um projeto de pesquisa de mestrado, e tem como objetivo analisar em que medida a Justiça Restaurativa pode ser utilizada a partir de uma perspectiva de política pública de enfrentamento e de prevenção da violência institucional nas prisões. Para tanto, verifica as consequências causadas pelo encarceramento em massa no Brasil, tendo como foco as violações a direitos fundamentais ocasionadas pela própria instituição. Posteriormente, busca compreender os pressupostos e o conceito da Justiça Restaurativa, levando em consideração a Resolução n 12/2002 da Organização das Nações Unidas. A partir daí, procura identificar qual a sua aplicabilidade na fase de execução da pena privativa de liberdade, classificando os modelos estabelecidos ao redor do mundo de acordo com o objetivo perseguido. Por fim, estuda de que forma a Justiça Restaurativa pode ser utilizada como ferramenta de enfrentamento e de prevenção à violência institucional no ambiente prisional, possibilitando uma filosofia penitenciária focada no diálogo e na redução da vulnerabilidade. $\mathrm{O}$ método utilizado é o hipotético-dedutivo, através do procedimento de revisão bibliográficadocumental, para uma adequada descrição do fenômeno estudado.
\end{abstract}

Palavras-Chave: Justiça Restaurativa. Violência institucional. Encarceramento em massa. Ambiente prisional.

\section{Resumen}

Este trabajo fue desarrollado a partir de un proyecto de investigación de maestría, y tiene como objetivo analizar en qué medida la Justicia Restaurativa puede ser utilizada desde una perspectiva de política pública de enfrentamiento y de prevención de la violencia institucional en las cárceles. Para ello, verifica las consecuencias causadas por el encarcelamiento masivo en Brasil, teniendo como foco las violaciones a derechos fundamentales ocasionadas por la propia institución. Posteriormente, busca comprender los presupuestos y el concepto de la Justicia Restaurativa, teniendo en cuenta la Resolución no 12/2002 de las Naciones Unidas. A partir de ahí, busca identificar cuál es su aplicabilidad en la fase de ejecución de la pena privativa de libertad, clasificando los modelos establecidos alrededor del mundo de acuerdo con el objetivo perseguido. Por último, estudia de qué forma la Justicia Restaurativa puede ser utilizada como herramienta de enfrentamiento y de prevención a la violencia institucional en el ambiente prisional, posibilitando una filosofía penitenciaria enfocada en el diálogo y en la reducción de la vulnerabilidad. El método utilizado es el hipotético-deductivo, a través del procedimiento de revisión bibliográfica-documental, para una adecuada descripción del fenómeno estudiado.

Palabras claves: Justicia Restaurativa. Violencia institucional. Encarcelamiento en masa. Medio ambiente prisión.

\section{Abstract}

This work was developed from a master's research project, and aims to analyze the extent to which Restorative Justice can be used from a public policy perspective to combat and prevent institutional violence in prisons. In

\footnotetext{
${ }^{1}$ Mestranda em Direitos Sociais pela Universidade Federal de Pelotas; RS; Brasil; asoiribarrem@gmail.com
} 
order to do so, it verifies the consequences caused by the mass incarceration in Brazil, focusing on violations of fundamental rights occasioned by the institution itself. Subsequently, it seeks to understand the presuppositions and the concept of Restorative Justice, taking into account UN Resolution 12/2002. From there, it seeks to identify its applicability in the execution phase of the custodial sentence, classifying the models established around the world according to the objective pursued. Finally, it studies how Restorative Justice can be used as an instrument to combat and prevent institutional violence in the prison environment, enabling a penitentiary philosophy focused on dialogue and reducing vulnerability. The method used is the hypothetical-deductive, through the procedure of bibliographical-documentary revision, for an adequate description of the phenomenon studied.

Keywords: Restorative Justice. Institutional violence. Mass Encarceration. Prison environment.

\section{Introdução}

O Brasil é o quinto país mais populoso do mundo, possuindo a terceira maior população carcerária, conforme o levantamento realizado pelo World Prision Brief (WPB). Além da crescente taxa de encarceramento, as prisões brasileiras não seguem nenhuma regra nacional ou internacional: existe um grande déficit de vagas, que gera a superlotação dos presídios, os presos são submetidos a celas não separadas de outras categorias, com péssimas condições de higiene e salubridade, abusos físicos e sexuais das mais variadas formas, bem como crescente problema das facções criminosas.

A Justiça Restaurativa foi reconhecida e recomendada pela Organização das Nações Unidas, na Resolução $\mathrm{n}^{\mathrm{o}}$ 12/2002, que a define como todo processo em que a vítima, o delinquente e, quando for o caso, qualquer outra pessoa ou membro da comunidade, afetados pela prática de uma infração penal, participem de forma ativa da resolução de questões derivadas do delito, em regra através do auxílio de um facilitador.

Como um conceito aberto e ainda em construção, nada impede o desenvolvimento de procedimentos restaurativos dentro dos estabelecimentos prisionais, envolvendo os ofensores, seus familiares e os próprios funcionários da administração penitenciária, minimizando o sofrimento dos indivíduos e buscando a concretização do direito social à assistência aos desamparados. Nessa perspectiva, pode servir como um instrumento das boas práticas - aqui entendidas como as medidas adotadas pelos agentes públicos com o intuito de garantir e preservar a dignidade da pessoa humana dos indivíduos submetidos à pena privativa de liberdade - de forma a combater e a prevenir a violência institucional no ambiente prisional.

\section{Justiça Restaurativa e violência institucional no ambiente prisional}

Primeiramente, antes de adentrar na questão de como a justiça restaurativa pode ser utilizada como instrumento de enfrentamento da violência institucional nas prisões, cumpre fazer algumas observações acerca da desumanidade das instituições carcerárias brasileiras. 


\subsection{Desumanidade nas prisões}

A questão da desumanidade nas prisões está intrinsecamente ligada à violência. Dessa forma, importa mencionar a análise sobre a violência realizada por Baratta (2013), sob o ponto de vista dos direitos humanos.

De acordo com a compreensão do autor, a origem das demais formas de violência, de forma direta ou indireta, é a violência estrutural, resultante da repressão das necessidades reais (e dos direitos humanos), a partir de seu conteúdo histórico-social.

Partindo dessa perspectiva, torna-se possível diferenciar outras formas de violência: violência individual seria aquela em que o agente é um único indivíduo; violência de grupo seria a originária de certo grupo social, composto por indivíduos particulares; na violência institucional o agente seria um órgão do Estado, um governo, o exército ou a segurança pública; por fim, na violência internacional, o agente é a administração de um Estado, dirigido ao governo e ao povo de outro Estado.

Assim, para este trabalho, a violência institucional segue o conceito do autor, para quem a violência institucional seria a perpetrada por um órgão do Estado, inclusive dentro de suas instituições.

Ainda, pode-se caracterizar outras formas de violência, de acordo com a forma através do qual é praticada (violência direta, indireta, física e moral) e contra quem é praticada (minorias étnicas, grupos marginalizados, mulheres, crianças, homossexuais etc.) (BARATTA, 2013, p. 339).

Nesse sentido, a prática de uma violência institucional pode ocorrer através da tortura. A garantia da vedação à tortura tem caráter absoluto, conforme o previsto na Convenção contra a Tortura e Outros Tratamentos ou Penas Cruéis, Desumanos ou Degradantes, não sendo possível invocar situações excepcionais, como ameaça ou estado de guerra, para sua justificação. Nesses termos, sua proibição integra as normas imperativas (jus cogens) do Direito Internacional, sendo hierarquicamente superior às demais normas internacionais (RAMOS, 2017).

Entretanto, apesar de seu caráter absoluto, as garantias contra a tortura e maus-tratos não adentram no sistema prisional brasileiro, que se mantém alheio às normas nacionais e internacionais e submete-se a suas próprias regras.

Em um relatório divulgado pela Pastoral Carcerária no ano de 2016, uma pequena amostragem demonstra uma situação alarmante: dos 105 casos de tortura analisados em 16 Estados, 52 foram praticados por servidores do sistema penitenciário, e nenhum resultou na 
responsabilização dos envolvidos. Ainda: 69\% das vítimas não foram ouvidas por juízes, defensores ou Ministério Público, e 100\% dos exames de corpo de delito apresentavam graves deficiências.

Frente a essa situação, o representante regional da América do Sul do Alto Comissariado das Nações Unidas para os Direitos Humanos (ACNUDH), Amerigo Incalcaterra, afirmou que a impunidade em casos de tortura praticados por agentes públicos contra presos se tornou a regra no sistema prisional brasileiro. Ressaltou, ainda, a ausência de dados apurando a incidência de tortura e tratamento cruel nas prisões brasileiras, o que caracteriza a falta de esforços para processar e castigar os responsáveis pelas referidas práticas, indo contra as recomendações internacionais.

Além do mais, segundo os dados disponibilizados pelo Levantamento Nacional de Informações Penitenciárias (INFOPEN), em junho de 2016, havia um total de 726.712 pessoas privadas de liberdade no Brasil, e um déficit de vagas de 358.663, gerando uma taxa de ocupação média de $197,4 \%$, o que significa que em cada espaço projetado para 10, são colocados 19 indivíduos.

Como resultado, recentemente foi declarado pelo Supremo Tribunal Federal, em decisão liminar na ADPF no 347/DF, o Estado de Coisas Inconstitucional em relação ao sistema carcerário brasileiro, instituto utilizado na Colômbia para indicar e buscar soluções para a violações em massa de direitos fundamentais, principalmente de direitos que exigem uma prestação programática por parte do Estado. A referida declaração serve para reforçar a gravidade da situação do cárcere no Brasil.

Dessa forma, percebe-se que o cárcere não é uma simples limitação da liberdade pessoal de circulação, mas uma instituição que gera as mais variadas aflições, diversas em cada estabelecimento e em relação a cada sujeito encarcerado.

Con la reclusión el condenado esarrojado, muy frecuentemente, en un infierno: en una sociedad salvaje, abandonada de hecho en gran parte al juego "libre" de las relaciones de fuerza y de poder entre detenidos y al desarrollo de una criminalidad carcelaria incontrolada que se ejercita sobre los más débiles e indefensos. Dentro de los muros de la cárcel, todo arbitrio, toda violencia, toda violación de derechos, toda lesión de la dignidad humana de las personas es posible (FERRAJOLI, 2016, p. 06).

Logo, na maior parte dos estabelecimentos carcerários os indivíduos que cumprem pena privativa de liberdade acabam em uma situação de sujeição, tanto em relação aos funcionários penitenciários quanto em relação aos demais reclusos, submetendo-se a regras que variam de uma instituição para outra e que disciplinam a maior parte de suas vidas. Como resultado, ocorre o que Pavarini (2008) denomina de coisificação do condenado. 
Para Ferrajoli (2016, p. 07), o cárcere equivale a uma contradição institucional. Constitui uma instituição criada pela lei e entregue ao controle do Estado, mas em cujo interior este está ausente, gerando um estado de natureza, no qual o que vale é a lei do mais forte. Perfaz, assim, um estabelecimento público, que tem como finalidade a custodia dos cidadãos, porém não consegue garantir os direitos fundamentais mais básicos em seu interior.

Nessa perspectiva, Pietro Costa (1974) entende que o cárcere, durante a formação do Estado Moderno, assumiu o formato de um espaço alheio ao direito: seria uma zona de não direito, um espaço livre e não hegemônico.

Frente a essa situação de desumanidade, cabe analisar estratégias de enfrentamento que possam, através de uma política pública, combater e prevenir a violência institucional. Dentre essas estratégias, pode-se citar a justiça restaurativa, que traz uma perspectiva de justiça inclusiva.

\subsection{Justiça Restaurativa}

Como resultado da crise estrutural e desumanidade do sistema criminal, surge a Justiça Restaurativa, como uma

(...) reação à perceptível ineficiência e alto custo (humano e financeiro) dos procedimentos da justiça convencional e, por outro, como uma reação ao fracasso desses sistemas convencionais em responsabilizar expressiva ou significativamente os infratores ou em atingir adequadamente as necessidades e interesses das vítimas (ACHUTTI, 2009, p. 71).

Dessa forma, a Justiça Restaurativa busca promover, frente a um conflito que se traduziu em um fato típico, uma solução dialogada, que envolva solidariedade e reconciliação. Abrange, assim, a vítima, o réu e a comunidade como um todo.

A Justiça Retributiva, difundida no sistema atual, considera que o crime é uma violação contra o Estado, pois envolve uma ação contrária à lei. Cabe, assim, à justiça determinar a culpa e infligir a pena. Na Justiça Restaurativa, no entanto, o crime também representa a dilaceração de um relacionamento entre ofensor e vítima, que mesmo sem possuírem uma relação anterior, acabam criando um vínculo, que em geral é hostil. Não sendo solucionado, esse relacionamento hostil afetará tanto o bem-estar da vítima quando o do ofensor (ZEHR, 2008).

Verifica-se, assim, como objetivos da Justiça Restaurativa a reparação para a vítima e o restabelecimento do relacionamento entre vítima e agressor, ampliando horizontes e oportunizando o arrependimento e o perdão.

Ressalta-se, porém, que 
Cura para as vítimas não significa esquecer e minimizar a violação. Implica num senso de recuperação, numa forma de fechar o ciclo. A vítima deveria voltar a sentir que a vida faz sentido e que ela está segura e no controle. O ofensor deveria ser incentivado a mudar. Ele ou ela deveriam receber a liberdade de começar a vida de novo. A cura abarca um senso de recuperação e esperança em relação ao futuro (COLET, 2011, p. 107).

Assim, a Justiça Restaurativa vai além da mera resposta punitiva à transgressão da lei. Permite que as partes afetadas participem diretamente do processo colaborativo, de forma a buscar o menor dano possível.

É importante destacar que a Justiça Restaurativa, apesar de sofrer certa influência das correntes abolicionistas, propõe a remodelação e complementação do sistema penal atual para uma maior e mais efetiva pacificação social. Prima, assim, pela dignidade da pessoa humana, não havendo a instrumentalização do homem em função do Estado.

A Justiça Restaurativa, dessa forma, busca abarcar no procedimento todas as partes envolvidas, procurando considerar seus motivos e anseios, sempre em busca da melhor solução para o conflito e da reparação do dano causado.

Essa reparação do dano envolve etapas previstas no programa proposto pela Justiça Restaurativa, englobando: a) mediação entre a vítima e o ofensor; b) conferência; c) círculos; d) assistência à vítima; e) assistência ao (ex)ofensor; f) restituição; g) serviço comunitário (COLET, 2011, p. 10).

Esse modelo permite que a justiça seja sentida pelas partes, que não participarão apenas como meras espectadoras. Busca-se, através delas, entender exatamente em que moldes o fato ocorreu, para compreender quais foram os danos causados e reestabelecer o equilíbrio social.

Buscando elaborar um conceito adequado, Howard Zehr traz a seguinte definição:

O primeiro passo na justiça restaurativa é atender às necessidades imediatas, especialmente as da vítima. Depois disso a justiça restaurativa deveria buscar identificar necessidades e obrigações mais amplas. Para tanto o processo deverá, na medida do possível, colocar o poder e a responsabilidade nas mãos dos diretamente envolvidos: a vítima e o ofensor (2008, p. 192).

Além do mais, é preciso levar em consideração que a Justiça Restaurativa possui um conceito aberto e fluido, a ser construído no decorrer das décadas, desde os primeiros estudos até agora. Inicialmente, envolvia apenas vítima e ofensor, passando a englobar as famílias e a comunidade, das mais variadas formas (mediação, conferências) e em todas as etapas do processo penal (PALLAMOLLA, 2009, p. 55).

Importa, ainda, mencionar a análise que Raffaella Pallamolla (2005, p. 55) faz de três concepções que são recapituladas por Johnstone e Van Ness. 
A primeira concepção envolve a noção de encontro, devendo ser oportunizada para a vítima, o ofensor e as partes interessadas a possibilidade de se encontrarem em um ambiente menos formal, sem a presença de especialistas. Por meio desse encontro, e através do auxílio de um facilitador, as partes assumem uma posição ativa para definirem, através do diálogo, qual decisão tomar a respeito do delito.

A segunda concepção é sobre reparação. Assim, através da justiça restaurativa, deve ser reparado o dano ocasionado à vítima. Nesse sentido, para aqueles que defendem essa concepção, não é necessário cominar dor ou sofrimento como retribuição ao ofensor, bastando a reparação. "Assim, quando um dano é cometido, a questão central não deveria ser 'O que devemos fazer ao ofensor?', ou 'O que o ofensor merece?', mas sim 'O que podemos fazer para corrigir a situação?"” (PALLAMOLLA, 2009, p. 57).

A última concepção trata sobre transformação. Assim, a finalidade primordial da justiça restaurativa seria a modificação da compreensão que as pessoas têm de si mesmas e a maneira como se relacionam umas com as outras.

Além do mais, Chris Marshall, Jim Boyack, e Helen Bowen (2004), ao estudarem a experiência da Nova Zelândia, enumeram alguns valores que são essenciais para a aplicação da justiça restaurativa, distinguindo-a das demais abordagens de resolução de conflitos, dentre os quais se pode citar a participação, o respeito, a honestidade, a humildade, a interconexão, o empoderamento, dentre outros.

A partir dessas observações, e conforme a Resolução 2002/12 da Organização das Nações Unidas, que define os princípios básicos para a utilização da justiça restaurativa em matéria criminal, importa analisar alguns conceitos.

O conceito de programa de justiça restaurativa está previsto no art. $1^{\circ}$ da referida resolução, segundo o qual consiste em qualquer programa restaurativo que utilize processos restaurativos com a finalidade alcançar resultados restaurativos. É perceptível que o conceito delineado inicialmente é muito aberto, encontrando delimitação nos artigos subsequentes.

Assim, o art. $2^{\circ}$ define o processo restaurativo, como qualquer processo no qual a vítima e o ofensor (e quaisquer outros indivíduos e membros da comunidade afetados pela prática da infração penal) participem de maneira ativa na resolução das questões, em geral através do auxílio de um facilitador. Dessa forma, os processos restaurativos podem incluir a mediação, a conciliação, a reunião familiar ou comunitária e os círculos decisórios.

No mesmo sentido, o resultado restaurativo está expresso no art. $3^{\circ}$, que o conceitua como um acordo a ser construído no transcorrer do processo restaurativo, incluindo respostas como a reparação, a restituição e o serviço comunitário, com a finalidade de atender as 
necessidades individuais e coletivas, de forma a alcançar a reintegração da vítima e do infrator.

O programa restaurativo pode ser aplicado em qualquer fase do procedimento criminal, o que possibilita sua utilização dentro do ambiente carcerário, apesar de algumas controvérsias em relação a ser (ou não) um ambiente propício para a obtenção de resultados restaurativos.

No entanto, diversas tentativas foram realizadas com o objetivo de introduzir as práticas restaurativas nas prisões, das mais modestas às mais ambiciosas. Van Ness (2018) trata sobre algumas delas, diferenciando-as de acordo com seus objetivos:

(1) Programas que objetivam auxiliar os prisioneiros a desenvolverem consciência e empatia pelas vítimas. Um exemplo é um programa desenvolvido em Hamburgo enfocado nos primeiros três meses dos prisioneiros na instituição, durante os quais são ajudados a refletir sobre a vitimização.

(2) Programas que possibilitam aos presos a oportunidade de repararem o dano causado às vítimas, ou mesmo de requerem essa reparação. Com esse objetivo, o International Centre for Prisions Studies in the UK iniciou um projeto de prisão restaurativa em três estabelecimentos, com a finalidade de propiciar oportunidades para os prisioneiros atuarem em serviços comunitários dentro e fora da prisão.

(3) Programas com o objetivo de facilitar a mediação entre prisioneiros e suas vítimas, suas famílias e suas comunidades. Um exemplo é o programa Prison Fellowship, em Camboja, que permite aos voluntários conversarem e facilitarem o relacionamento entre os prisioneiros e os membros de suas famílias.

(4) Programas com a finalidade de fortalecer os laços entre os prisioneiros e a comunidade onde vivem. Um exemplo é o programa desenvolvido pelo International Centre for Prisions Studies in the UK..

(5) Programas de desenvolvimento de uma cultura segundo a qual os conflitos existentes no ambiente prisional são resolvidos pacificamente. Um programa adotado em Ohio, nos Estados Unidos, persegue esse objetivo, permitindo que alguns prisioneiros, que são treinados para serem mediadores, ajudem outros prisioneiros em conflito a encontrar a solução pacífica.

(6) Programas que pretendem criar um ambiente onde os presos possam ser inteiramente transformados. Ocasionariam a criação de uma "prisão virtuosa". O principal problema desses programas está no fato de que o ambiente prisional vai no sentido contrário a essa transformação. 
Após a compreensão acerca do conceito e âmbito de aplicação da justiça restaurativa, cabe discorrer sobre sua importância como política pública de combate e prevenção à violência institucional nas prisões.

\subsection{Justiça restaurativa na perspectiva de enfrentamento à violência institucional}

Primeiramente, importa mencionar que a própria Lei de Execução Penal (LEP), no ordenamento brasileiro, impõe, em seu art. 10, o dever do Estado de prestar assistência ao preso e ao internado, com o objetivo de prevenir o crime e orientar o retorno à convivência em sociedade.

Percebe-se que a previsão normativa traz uma visão minimizadora de danos. Nessa perspectiva, Zaffaroni (1991) trata sobre a necessidade de elaboração de uma filosofia penitenciária de tratamento humano redutor da vulnerabilidade, que ocasione a diminuição ao mínimo possível das consequências deteriorantes decorrentes do cárcere.

Entretanto, antes de aprofundar os ensinamentos de Zaffaroni, é inevitável mencionar a crise do Estado Social, ocorrida simultaneamente com a expansão do sistema penal, que atinge diretamente a estrutura das prisões, principalmente em relação à vulnerabilização dos reclusos.

Segundo Garland (2008), a partir da modernidade recente, os dispositivos contemporâneos de controle do crime passaram a ser moldados por forças sociais, que ingressam na agenda política - o denominado populismo penal - trazendo soluções fáceis para as reivindicações da sociedade.

Nesse contexto de transição, segundo Loïc Wacquant (2001, p. 09), surge um paradoxo decorrente da penalidade neoliberal, que "pretende remediar com um "mais Estado" policial e penitenciário o "menos Estado" econômico e social que é a própria causa da escalada generalizada da insegurança objetiva e subjetiva em todos os países [...]”. É nesse sentido que o autor fala em transição de um Estado Social para um Estado Penal.

Como resultado, além da expansão da população encarcerada, os direitos fundamentais são cada vez mais desvalorizados, principalmente em relação ao sistema penitenciário.

Além do mais, com o objetivo de atender ao direito social à assistência dos presos, a própria LEP adota um discurso ressocializador. Entretanto, nas palavras de Zaffaroni (1991, p. 10), o referido discurso não é uma utopia, mas um absurdo. Para o autor, a submissão dos indivíduos às instituições carcerárias produz efeitos deteriorantes que nunca poderão ser totalmente suprimidos, razão pela qual nunca poderá ser atingido o efeito ressocializador. 
Como consequência, deve haver a substituição do discurso ressocializador pelo tratamento humano redutor da vulnerabilidade.

A prisionização é o processo de deterioro que opera de modo contrário, ou seja, que normalmente aumenta a vulnerabilidade. É muito difícil imaginar que esse processo possa reverter-se, dadas as características estruturais da prisão. De qualquer maneira, não é de todo impossível pensar numa planificação da atividade da agência penitenciária que se oriente para um tratamento humano que procure não incrementar a vulnerabilidade, na medida do possível, reduzir seus níveis (ZAFFARONI, 1991, p. 18).

Uma parcela do mencionado tratamento redutor de vulnerabilidade seria atribuída ao próprio pessoal penitenciário, através de relações mais reais e sinceras entre o operador e o preso, desprovidas de argumentos moralizantes e estereotipados (ZAFFARONI, 1991, p. 18).

Nesse sentido, pode-se pensar nos valores restaurativos como instrumentos úteis a essa forma de tratamento. A implementação de uma justiça mais participativa, através da Justiça Restaurativa, de forma a enfrentar e prevenir a violência institucional no ambiente carcerário, ocasiona, decisivamente, a diminuição da vulnerabilidade dos presos, servindo de garantia à integridade física e psicológica e minimizando os efeitos degradantes ocasionados pela pena privativa de liberdade.

\section{Conclusões}

A violência configura um fenômeno complexo, no qual a violência institucional constitui apenas mais uma das formas de manifestação. No ambiente carcerário, gera uma desvalorização crônica de direitos fundamentais, perfazendo uma situação de desumanidade. No mesmo sentido, seu enfrentamento também deve levar em consideração políticas públicas multifacetadas, que permitam atingir diversos aspectos dessa realidade.

A justiça restaurativa vai além de uma simples resposta punitiva. É considerada um conceito ainda aberto, em construção, que através da aplicação de seus valores permite que as partes afetadas participem de maneira ativa do processo colaborativo, em busca do menor dano possível. Dessa forma, pode-se pensar na utilização de procedimentos restaurativos no ambiente prisional como forma de implementação de uma política pública de combate e de prevenção à violência institucional, resultando na diminuição da vulnerabilização dos presos e minimizando os efeitos degradantes ocasionados pela pena.

\section{Referências}

ACHUTTI, Daniel. Modelos Contemporâneos de Justiça Criminal: Justiça Terapêutica, Instantânea e Restaurativa. Porto Alegre: Livraria do Advogado, 2009. 
BARATTA, Alessandro. Criminología y sistema penal. Buenos Aires: BdeF, 2013.

BRASIL. Ministério da Justiça e Segurança Pública, Levantamento Nacional de Informações Penitenciárias INFOPEN - Junho de 2016. Disponível em: < https://www.poder360.com.br/wp-content/uploads/2017/12/relatorio_2016_Junho.pdf>.

Acesso em: jan de 2018.

COLET, Charlise Paula; CALlEGARI, Andre Luis. Direito Penal e Globalização Sociedade do Risco, Imigração Irregular e Justiça Restaurativa. Porto Alegre: Livraria do Advogado, 2011.

COSTA, Prietro. Il Progetto Giuridico. Ricerche sulla giurisprudenza del liberalismo clássico (Vol. I Da Hobbes a Bentham). Milano: Giuffrè Ed., 1974.

FERRAJOLI, Luigi. Jurisdicción y ejecución penal. La cárcel: una contradicción institucional. Disponível em: < http://revistes.ub.edu/index.php/CriticaPenalPoder/article/view/16783>. Acesso em: jan de 2018.

GARLAND, David. A cultura do controle: crime e ordem social na sociedade contemporânea. Rio de Janeiro: Revan, 2008.

INTERNATIONAL CENTRE FOR PRISON STUDIES. World Prison Brief - Entire world Prison Population Totals. Disponível em: <http://www.prisonstudies.org/info/worldbrief/wpb_stats.php?area=all\&category=wb_popto tal>. Acesso em agosto de 2017.

MARSHALL, Chris; BOYACK, Jim; BOWEN, Helen. Como a Justiça Restaurativa assegura a boa prática - Uma Abordagem Baseada em Valores. In: Slakmon, C., R. De Vitto, e R. Gomes Pinto, org. Justiça Restaurativa. Brasília - DF: Ministério da Justiça e Programa das Nações Unidas para o Desenvolvimento - PNUD, 2005.

PALLAMOLLA, Raffaella da Porciuncula. Justiça restaurativa: da teoria à prática 1.ed. São Paulo: IBCCRIM, 2009.

PAVARINI, Massimo. Estrategias de lucha. Los derechos de los detenidos y el abolicionismo. Delito y Sociedad. Revista de Ciencias Sociales. Año 17, n. 26, 2008.

RAMOS, André de Carvalho. Curso de Direitos Humanos - 4 ed. São Paulo: Saraiva, 2017.

Relatório divulgado pela Pastoral Carcerária Nacional. Disponível em: <http://carceraria.org.br/wp-content/uploads/2017/03/Relatorio-Tortura-2016.pdf>. Acesso em: jan de 2018.

VAN NESS, Daniel W. Restorative Justice in Prisons. Disponível em: < http://restorativejustice.org/am-site/media/restorative-justice-in-prison.pdf $>$. Acesso em: julho de 2018.

WACQUANT, Löic. As prisões da miséria. Rio de Janeiro: Jorge Zahar, 2001. 
ZAFFARONI, Eugenio Raul. A filosofia do sistema penitenciário. Cuadernos de la Cárcel. Buenos Aires, 1991.

ZEHR, Howard. Trocando as lentes: um novo foco sobre o crime e a justiça. Tradução de Tônia Van Acker. São Paulo: Palas Athena, 2008. 